NBER WORKING PAPER SERIES

\title{
PRODUCTTVITY MEASUREMENT FOR A DISTRIBUTION FIRM
}

\author{
W. Erwin Diewert \\ Ann Marie Smith
}

Working Paper No. 4812

\section{NATIONAL BUREAU OF ECONOMIC RESEARCH 1050 Massachusetts Avenue Cambridge, MA 02138 \\ July 1994}

The first author is a Professor of Economics at the University of British Columbia and a research associate of the NBER. He thanks the SSHRC of Canada for research support. The second author is a recent graduate of the University of British Columbia. This paper is part of NBER's research program in Productivity. Any opinions expressed are those of the authors and not those of the National Bureau of Economic Research.

(C) 1994 by W. Erwin Diewert and Ann Marie Smith. All rights reserved. Short sections of text, not to exceed two paragraphs, may be quoted without explicit permission provided that full credit, including () notice, is given to the source. 


\title{
PRODUCTIVITY MEASUREMENT \\ FOR A DISTRIBUTION FIRM
}

\begin{abstract}
The paper derives a consistent accounting framework for the treatment of inventories when measuring the productivity of a distribution firm. The average purchase price of an inventory item during an accounting period must be distinguished from its average selling price and these two average prices should be distinguished from the corresponding balance sheet prices. The accounting framework is implemented for a distribution firm which sold 76,000 separate items. The firm achieved a 9.6 percent per quarter total factor productivity growth rate over 6 quarters.
\end{abstract}

W. Erwin Diewert Department of Economics University of British Columbia \#997-1873 East Mall Vancouver, BC V6T 2W1 CANADA and NBER

\author{
Ann Marie Smith \\ Columbia Distributors, Ltd. \\ Dustbane Products \\ 1220 SE Marine Drive \\ Vancouver, BC V5X 2W1 \\ CANADA
}




\section{Introduction}

Most industry productivity studies have focused on firms or industries in the manufacturing sector. However, in many countries, the trade sector (which includes both wholesale and retail trade) has grown faster than the manufacturing sector. ${ }^{1}$ There are concerns expressed that this shift from manufacturing to services will slow the overall productivity growth of the economy because it is believed that it is not possible to make large productivity improvements in the service sector. However, the evidence on the low total factor productivity of the trade and distribution sector is somewhat inconclusive since it relies on highly aggregated national accounts data. ${ }^{2}$

This paper will attempt to cast some light on the above issues by measuring the total factor productivity of a large appliance parts distributor in Western Canada. ${ }^{3}$ This firm keeps detailed data on every inventory transaction for a 21-month period. Thanks to the cooperation of the owner, these data were made available to us and we were able to build up a detailed set of economic accounts for seven consecutive quarters starting at the second quarter of 1988 .

In Section 2 below, we develop an accounting framework for inventories which should be of interest to both management accountants and national income accountants. ${ }^{4}$ We find that the treatment of inventories in a distribution firm is a complex matter: an individual inventory item transaction could appear as either (i) a sale of final output or (ii) a purchase of an intermediate input or (iii) a net addition to the firm's inventory stocks or (iv) as a capital stock component which yields capital services to the firm during the accounting period under examination.

In Section 3, we extend the accounting framework developed in Section 2 to include the treatment of noninventory capital stock inputs to the firm, such as furniture and office equipment, computers and storage space.

Given that we have decomposed the value flows of the distribution firm into price and quantity components in accordance with the accounting framework explained in Sections 2 and 3 , Section 4 considers how exactly the productivity of the firm should be measured. We follow Diewert [1992] and measure the productivity change of the firm over two consecutive

1 For example, in Canada, the trade sector has increased from $11.5 \%$ of GDP in 1971 to $13.5 \%$ in 1986 ; see Statistics Canada [1988].

2 The problem is that national statistical agencies have not been given the resources to measure service sector inputs and outputs as accurately as the manufacturing sector.

3 The firm has outlets in seven locations: Vancouver, Victoria, and Coquitlam in British Columbia; Edmonton and Calgary in Alberta; Saskatoon in Saskatchewan and Winnipeg in Manitobe.

4 The United Nation's $[1968 ; 110-111]$ early treatment of inventories or stocks focused on valuing net changes in stocks held over the period under consideration. The new System of National Accountants 1993 , United Nations $[1993 ; 130-133 ; 217-221 ; 230-233 ; 278-286]$ has a much more satisfactory treatment of inventories, but since interest is still treated as a transfer payment, the user cost of inventories is not developed. Historical cost accounting is also deficient in that no allowance for asset inflation is made. 
periods as the ratio of the Fisher [1922] ideal output quantity index divided by the Fisher ideal input inclex.

Section 5 presents our empirical results and Section 6 concludes.

\section{Accounting for Inventories}

In this section, we shall assume that the only durable inputs owned by the firm are inventories; all other durable inputs (such as buildings or computers) are rented or leased.

The period $t$ cash flow of the firm, $C F^{t}$, is defined as follows:

$$
C F^{t} \equiv \Sigma_{m=1}^{M} P_{m}^{t} Z_{m}^{t}+\Sigma_{n=1}^{N} P_{S_{n}}^{t} S_{n}^{t}-\Sigma_{n=1}^{n} P_{I_{n}}^{t} I_{n}^{t}
$$

where: $P_{m}^{t}>0$ is price for period $t$ of the $m$ th noninventory output (or input) produced (or used) by the firm; $Z_{m}^{\ell}$ is the quantity of the $m$ th noninventory output produced by the firm if $Z_{m}^{t}>0$ (if $Z_{m}^{t}<0$, then $-Z_{m}^{t}$ is the quantity of the $m$ th good used as an input during period $t) ; S_{n}^{t} \geq 0$ is the quantity of the $n$th inventory good which is sold by the firm during period $t$ and $P_{S_{n}}^{t} \geq 0$ is the corresponding average price; $I_{n}^{t} \geq 0$ is quantity of the $n$th inventory good which is purchased by the firm during period $t$ and $P_{I_{n}}^{t} \geq 0$ is the corresponding average price.

At the beginning of the period $t$, we assume that the only assets held by the firm are its stocks of inventory items. Of course, end of period stocks of inventories are equal to the beginning of next period's stocks of inventories. We define $A^{t}$ to be the value of the firm's physical stocks of inventories at the end of the period $t$. Thus we have:

$$
A^{t} \equiv \sum_{n=1}^{N} P_{K_{n}}^{t} K_{n}^{t}
$$

where $K_{n}^{t} \geq 0$ is the firm's holdings of the $n$th inventory good at the end of period $t$ and $P_{K_{n}}^{t} \geq 0$ is the corresponding end of period $t$ price. In our empirical work, this price was taken to be the last purchase price for this good in period $t$. Thus in situations where inflation occurs during period $t, P_{K_{n}}^{t}$ (the last price paid) will generally be higher than $P_{I_{n}}^{t}$ (the average purchase price during the period). Of course, the average selling price for good $n$ in period $t, P_{S_{n}}^{\ell}$, will generally be higher than $P_{I_{n}}^{t}$, the average purchase price (the difference $P_{S_{n}}^{t}-P_{I_{n}}^{t}$ is called the trade margin).

Note that our choice of $P_{K_{n}}^{t}$ as the price of the last purchase price of the $n$th inventory good in period $t$ is consistent with the original aim of balance sheet accounting, which was to give an accurate picture of the value of the firm's assets (and liabilities) at a particular moment in time (the end of the accounting period). Thus the balance sheet or stock price $P_{K_{n}}^{t}$ will generally be different from the flow prices $P_{S_{n}}^{t}$ and $P_{I_{n}}^{t}$.

Note that we are attempting to value assets at time $t$ at the relevant opportunity costs prevailing at the moment of time. Thus our inventory value $A^{t}$ is a current cost asset value and it differs from the traditional accounting historical cost asset value which values all assets at their historical cost of acquisition. Of course, in periods of moderate 
or rapid inflation, historical cost asset values do not lead to accurate values of either the firm's current asset value or current income.

We now turn our attention to the problems involved in defining the distribution firm's income or profits. Ex post current cost accounting income in period $t$ for our distribution firm can be defined as period $t$ cash flow plus the end of period $t$ asset value minus the beginning of period $t$ asset value; i.e. define $A I^{t}$ as follows:

$$
A I^{t} \equiv C F^{t}+A^{t}-A^{t-1} \text {. }
$$

Thus accounting income equals cash flow plus the increment in asset value over the period.

However, accounting income as defined by (3) is not a satisfactory measure of income or pure profits for an equity financed firm: the problem is that $A I^{t}$ neglects the opportunity cost of capital. Thus we define ex post economic income in period $t$ as

$$
E I^{t} \equiv C F^{t}+A^{t}-\left(1+r_{t}\right) A^{t-1}
$$

where $r_{t}$ is the firm's opportunity cost of capital at the beginning of period $t$. Thus economic income is smaller than accounting income by the term $r_{t} A^{t-1}$ which is either the interest cost of borrowing $A^{t-1}$ dollars at the beginning of period $t$ for a debt financed furm or it is the period $t$ interest earnings that are foregone by an equity financed firm by not lending out its beginning of period $t$ value of assets, $A^{t-1}$.

Economic income or pure profits $E I^{t}$ defined by (4) can serve as an objective function for period $t$

Definition (4) is the key to our treatment of inventories. However, before we can spell out the implications of (4), we need another set of equations which relate the end of period $t$ stocks of inventory good $n, K_{n}^{t}$, to the corresponding beginning of period $t$ stock, $K_{n}^{t-1}$ :

$$
K_{n}^{t}=K_{n}^{t-1}+I_{n}^{t}-S_{n}^{t}-U_{n}^{t}, \quad n=1,2, \ldots, N,
$$

where $U_{n}^{t}$ denotes the number of units of inventory good $n$ that are internally used up or utilized by the firm during period $t .^{5}$ This number includes losses due to theft, spoilage and accidental damage and defects. Note that $I_{n}^{t}-S_{n}^{t}-U_{n}^{t}$ is equal to net additious to the stock of inventories for good $n$ during period $t$. Thus equation $n$ in (5) says that the end of period $t$ stock of good $n$ equals the beginning of period $t$ stock plus net additions during period $t$ (which could be positive or negative).

Now substitute (1), (2) and (5) into (4) to obtain the following expression for period $t$ economic income or pure profits:

$$
\begin{aligned}
E I^{t} & =\sum_{m=1}^{M} P_{m}^{t} Z_{m}^{t}+\sum_{n=1}^{N} P_{S_{n}}^{t} S_{n}^{t}-\sum_{n=1}^{N} P_{I_{n}}^{t} I_{n}^{t} \\
& +\sum_{n=1}^{N} P_{K_{n}}^{t}\left[K_{n}^{t-1}+I_{n}^{t}-S_{n}^{t}-U_{n}^{t}\right]-\left(1+r_{t}\right) \sum_{n=1}^{N} P_{K_{n}}^{t-1} K_{N}^{t-1}
\end{aligned}
$$

5 Some units of inventory good $n$ may be transformed by the firm into units of some other final output, $Z_{m}^{t}$ say. Thus $U_{n}^{t}$ would include these units of transformed good $n$. In our empirical work, our firm did not engage in this type of (manufacturing) activity. 


$$
\begin{aligned}
& =\sum_{m=1}^{N} P_{m}^{t} Z_{m}^{t}+\sum_{n=1}^{N} P_{S_{n}}^{t} S_{n}^{t}-\sum_{n=1}^{N} P_{I_{n}}^{t} I_{n}^{t} \\
& +\sum_{n=1}^{N} P_{K_{n}}\left[I_{n}^{t}-S_{n}^{t}-U_{n}^{t}\right]-\sum_{n=1}^{N}\left[r_{t} P_{K_{n}}^{t-1}-\left(P_{K_{n}}^{t-1}-P_{K_{n}}^{t-1}\right)\right] K_{n}^{t-1}
\end{aligned}
$$

There are five sets of terms on the right hand side of (7). The first set of terms, $\sum_{m=1}^{M} P_{n}^{t} Z_{m}^{t}$, reflects the sale of noninventory outputs and the purchases of noninventory inputs during period $t$. The next four sets of terms are all inventory related: (i) $\sum_{n=1}^{N} P_{S_{n}}^{t} S_{n}^{t}$ is the value of inventory sales during period $t$; (ii) $\sum_{n=1}^{N} P_{I_{n}}^{t} I_{n}^{t}$ is the value of inventory purchases during the period; (iii) $\sum_{n=1}^{N} P_{K_{n}}^{t}\left[I_{n}^{t}-S_{n}^{t}-U_{n}^{t}\right]$ is the value of net additions to inventory stocks made during the period valued at end of period $t$ prices (if $I_{n}^{t}-S_{N}^{t}-U_{n}^{t}>0$, then the $n$th term in the sum corresponds to an output while if $I_{n}^{t}-S_{n}^{t}-U_{n}^{t}<0$, then we have an input term); and (iv) $\sum_{n=1}^{N}\left[r_{t} P_{K_{n}}^{t-1}-\left(P_{K_{n}}^{t}-P_{K_{n}}^{t-1}\right)\right] K_{n}^{t-1}$ are the net costs of holding the initial stock of inventories for period $t$.

Define the period $t$ ex post user cost for inventory good $n$ as

$$
\alpha_{n}^{t} \equiv\left[r_{t} P_{K_{n}}^{t-1}-\left(P_{K_{n}}^{t}-P_{K_{n}}^{t-1}\right)\right], \quad n=1, \ldots, N .
$$

Note that $\alpha_{n}^{t}$ equals an interest cost $r_{t} P_{K_{n}}^{t-1}$ less capital gains $P_{K_{n}}^{t}-P_{K_{n}}^{t-1}$. Thus $\alpha_{n}^{t}$ is a discrete time analogue to the continuous time Jorgenson [1963] user cost of capital. ${ }^{6}$ If all of the user costs $\alpha_{n}^{t}$ are positive, then the last set of terms on the right hand side of (7) are cost items and $K_{n}^{t-1}$ should be regarded as an input with price equal to $\alpha_{n}^{t}$.

The above accounting treatment of inventories is quite different from both the United Nation's treatment of inventories as well as traditional historical cost accounting treatments.

Before we deal with noninventory assets, it is worth pointing out that maximizing a discounted stream of economic incomes is equivalent to maximizing a discounted stream of cash fows. To see this, assume that the firm's starting asset value is $A^{0}$ at the beginning of period 1 and the firm sells off its assets $A^{T}$ at the end of period $T$. Then the firm's discounted stream of market transactions is

$$
\begin{aligned}
E I \equiv & -A^{0}+\left(1+r_{1}\right)^{-1} C F^{1}+\left(1+r_{1}\right)^{-1}\left(1+r_{2}\right)^{-1} C F^{2}+\ldots \\
& +\left(1+r_{1}\right)^{-1}\left(1+r_{2}\right)^{-1} \ldots\left(1+r_{T}\right)^{-1}\left[C F^{T}+A^{T}\right] \\
& =\left(1+r_{1}\right)^{-1} E I^{1}+\left(1+r_{1}\right)^{-1}\left(1+r_{2}\right)^{-1} E I^{2}+\ldots \\
& +\left(1+r_{1}\right)^{-1}\left(1+r_{2}\right)^{-1} \ldots\left(1+r_{T}\right)^{-1} E I^{T}
\end{aligned}
$$

6 We can obtain closer correspondence to Jorgenson's user cost if we define the depreciation rates $\delta_{n}^{t} \equiv U_{n}^{t} / K_{n}^{t-1}$ for $n=1, \ldots, N$. Then we may replace $U_{n}^{t}$ in (7) by $\delta_{n}^{t} K_{N}^{t-1}$ for $n=1, \ldots, N$. After these replacements, the last two terms in (7) may be rewritten as $\sum_{n=1}^{N} P_{K_{n}}^{t}\left[I_{n}^{t}-S_{n}^{t}\right]-\sum_{n=1}^{N}\left[r_{t} P_{K_{n}}^{t-1}+\delta_{n}^{t} P_{K_{n}}^{t}-\right.$ $\left(P_{K_{n}}^{t}-P_{K_{n}}^{t-1}\right) \mid K_{n}^{t-1}$. Thus the user cost $\alpha_{n}^{t}$ can be replaced by the user cost $\rho_{n}^{t} \equiv\left[r_{t} P_{K_{n}}^{t-1}+\delta_{n}^{t} P_{K_{n}}^{t}-\left(P_{K_{n}}^{t}-\right.\right.$ $\left.\left.P_{K_{n}}^{t-1}\right)\right]$ which is an exact analogue to Jorgenson's user cost, taking into account the complications due to discrete time data. In fact, this is the discrete time formula for user cost that was used by Christensen and Jorgenson [1969], neglecting the complications due to the taxation of business income. 
where (10) follows from (9) using definitions (4). Thus maximizing discounted cash flows is equivalent to maximizing discounted economic incomes. We turn now to the accounting treatment of noninventory durable inputs that might be held by the firm.

\section{Accounting for Noninventory Capital Inputs}

The accounting framework that we developed in the previous section for inventory goods can readily be adapted to deal with the firm's purchases of other durable inputs. ${ }^{7}$ We now assume that our list of $N$ capital inputs includes noninventory durable inputs as well.

Recall the utilization terms $U_{n}^{t}$ that occurred in equations (5) above. If capital good $n$ is a noninventory capital good, then we now interpret $U_{n}^{t}$ as a combination of the physical loss of efficiency of the beginning of the period capital stock $K_{n}^{t-1}$ and the retirement or scrapping of older units of this initial capital stock that occurred during period $t$. We further follow the example of Jorgenson [1963] and Jorgenson and Griliches [1967; 256-257] and assume that $U_{n}^{t}$ is a constant fraction $\delta_{n}$ of the initial capital stock; i.e., we assume that

$$
U_{n}^{t}=\delta_{n} K_{n}^{t-1}
$$

for all noninventory capital goods $n$. Thus $\delta_{n}$ is the noninventory capital good $n$ depreciation or deterioration rate where $0 \leq \delta_{n}<1$. If $n$ is a noninventory capital good and we substitute (11) into the capital accumulation equations (5), we obtain the following equations:

$$
K_{n}^{t}=\left(1-\delta_{n}\right) K_{n}^{t-1}+I_{n}^{t}-S_{n}^{t}
$$

where $I_{n}^{t}$ equals the number of units of capital good $n$ purchased during period $t$ and $S_{n}^{t}$ equals the number of units sold during period $t^{8}$

In order to further simplify the algebra of our model, if good $n$ is a noninventory capital good, we assume that

$$
P_{I_{n}}^{t}=P_{S_{n}}^{t}=P_{K_{n}}^{t}
$$

i.e, the average purchase price for noninventory capital good $n$ in period $t, P_{I_{n}}^{t}$, is equal to the average selling price for good $n$ in period $t, P_{S_{n}}^{t}$, which in turn is equal to the end of period $t$ asset value for noninventory capital $\operatorname{good} n, P_{K_{n}}^{t}$. If $\operatorname{good} n$ is a noninventory capital good and we substitute (11) and (13) into (7), we find that the terms involving capital good $n$ simplify as follows:

$$
\begin{aligned}
P_{S_{n}}^{t} & S_{n}^{t}-P_{l_{n}}^{t} I_{n}^{t}+\left[I_{n}^{t}-S_{n}^{t}-U_{n}^{t}\right]-\left[r_{t} P_{K_{n}}^{t-1}-\left(P_{K_{n}}^{t}-P_{K_{n}}^{t-1}\right)\right] K_{n}^{t-1} \\
& =\left[r_{t} P_{I_{n}}^{t-1}+\delta_{n} P_{l_{n}}^{t}-\left(P_{l_{n}}^{t}-P_{l_{n}}^{t-1}\right)\right] K_{n}^{t-1} \\
& =\beta_{n}^{t} K_{n}^{t-1}
\end{aligned}
$$

7 We define a durable input to be an input which is not completely used up in the accounting period in which it was purchased.

8 Typically, $S_{n}^{t}$ will equal 0 for a noninventory capital good. 
where the period $t$ ex post accounting user cost of capital for noninventory capital good $n$ is defined as

$$
\beta_{n}^{t} \equiv\left[r_{t} P_{I_{n}}^{t-1}+\delta_{n} P_{I_{n}}^{t-1}-\left(P_{I_{n}}^{t}-P_{I_{n}}^{t-1}\right)\right]
$$

Thus if good $n$ is a noninventory durable input, then the four terms involving this good in the definition of period $t$ economic income $E I^{t}$ collapse down to the single term $\beta_{n}^{t} K_{n}^{t-1}$ under the simplifying assumptions (11) and (13). The user cost of capital for good $n, \beta_{n}^{t}$, is made up three terms: (i) the interest $\operatorname{cost} r_{t} P_{I_{n}}^{t-1}$; (ii) the depreciation $\operatorname{cost} \delta_{n} P_{I_{n}}^{t}$ and (iii) a minus capital gains term, $-\left(P_{I_{n}}^{t}-P_{I_{n}}^{t-1}\right)$. This is analogous to the Jorgenson and Griliches $[1967 ; 256]$ continuous time user cost of capital and is in fact equal to the Christensen and Jorgenson [1969] discrete time user cost of capital (neglecting the complications due to business income taxation).

It should be noted that our treatment of noninventory capital inputs follows the net capital methodology pioneered by Jorgenson and Griliches [1967; 256] as opposed to the gross capital methodology used by many statistical agencies. In the net capital methodology, the quantity of capital services supplied by older units of capital is reduced by depreciation and the user costs associated with all vintages of capital in use during a given period remain constant; in a correct gross capital methodology, the quantity of capital services supplied by an older unit of capital remains equal to its initial installed capacity until it is retired but the user costs of older units of capital would be less than the user costs of younger units due to the decline in asset value which occurs as the capital good ages.

To summarize this section and the previous section, we note that the decomposition of income in period $t$ given by (7) into price and quantity components forms the basis for our productivity computations, with the understanding that the simplification given by (14) occurs if capital good $n$ is a noninventory durable input. We treated inventories differently from other capital inputs because price information on the three price series $P_{I_{n}}^{t}, P_{S_{n}}^{t}$ and $P_{K_{n}}^{t}$ is readily available from firm records. For other capital inputs, information on these three types of prices is not available from firm records due to the infrequent nature of noninventory capital input purchases. Thus for noninventory capital inputs, we are forced to make the simplifying assumptions in (13) and we obtain the required information on $P_{I_{n}}^{t}$ by using relevant price indexes from government statistical agencies. ${ }^{9}$

\section{Productivity Indexes}

Rewrite economic income in period $t$, given by (7) above, as follows:

$$
E I^{t}=p^{t} \cdot y^{t}-w^{t} \cdot x^{t}, \quad t=1,2, \ldots, T
$$

9 We are also required to make educated guesses as to the magnitudes of the noninventory depreciation rates $\delta_{n}$. 
where $p^{t}$ and $w^{t}$ are positive price vectors, $y^{t}$ is a net output vector, $x^{t}$ is a positive vector of labor and capital inputs used by the firm in period $t$ and $p^{t} \cdot y^{t} \equiv \sum_{i=1}^{I} p_{i}^{t} y_{i}^{t}$ denotes the inner product of the vectors $p^{t}$ and $y^{t}$. The $y^{t}$ vector contains the outputs produced by the firm in period $t$ (these components of $y^{t}$ have positive signs) and the intermediate inputs used by the firm in period $t$ (these components have a negative sign). Thus components of $y^{t}$ consist of the $S_{n}^{t}$ (sales of inventory items), the $I_{n}^{t}-S_{n}^{t}-U_{n}^{t}$ (net additions to inventory stocks which could be positive or negative), the terms $-U_{n}^{t}$ (minus purchases of inventories). and other terms $Z_{m}^{t}$ (minus purchases of business services and minus purchases of shipping services). The components of the $x^{t}$ vector consist of the $K_{n}^{t}$ (initial stocks of inventories and other capital inputs which are furniture and fixtures, computers and buildings) and one $Z_{m}^{t}$ (manhours utilized during period $t$ ). The prices which correspond to these quantities can be determined by inspecting equations (7) and (14).

An index of the productivity going from period $t-1$ to period $t$ can be defined as a (net) output index divided by an input index; i.e., we define productivity in period $t$ to be:

$$
P R O D^{t} \equiv Q_{F}\left(p^{t-1}, p^{t}, y^{t-1}, y^{t}\right) / Q_{F}^{*}\left(w^{t-1}, w^{t}, x^{t-1}, x^{t}\right) \quad \text { for } t=2,3, \ldots, T,
$$

where $Q_{F}$ and $Q_{F}^{*}$ are Fisher [1922] ideal quantity indexes; i.e.,

$$
\begin{gathered}
Q_{F}\left(p^{t-1}, p^{t}, y^{t-1}, y^{t}\right) \equiv\left[y^{t-1} \cdot y^{t} p^{t} \cdot y^{t} / p^{t-1} \cdot y^{t-1} p^{t} \cdot y^{t-1}\right]^{\frac{1}{2}} \\
Q_{F}^{*}\left(w^{t-1}, w^{t}, x^{t-1}, x^{t}\right) \equiv\left[w^{t-1} \cdot x^{t} p^{t} \cdot x^{t} / w^{t-1} \cdot x^{t-1} w^{t} \cdot x^{t-1}\right]^{\frac{1}{2}}
\end{gathered}
$$

For justifications for the use of the Fisher ideal index number formula in (17), see Diewert [1992].

The firm whose productivity performance we will examine in the next section has 76,000 separate inventory' items that it sells to customers. Since all inventory items appear three times in the $y^{t}$ vectors and once in the $x^{t}$ vectors, it can be seen that the computation of the inner products in (18) and (19) is not trivial. To simplify our computations, we used a two stage procedure. In the first stage, we constructed separate Fisher chain price and quantity indexes for: (i) sales of inventories; (ii) purchases of inventories; (iii) net additions to the stocks of inventories held; and (iv) capital utilization of beginning of the period stocks of inventories held. In the second stage, we aggregated the first three inventory aggregates with business services and shipping services using the Fisher ideal index number formula where each price and quantity vector now has only five components. We also aggregated the aggregate capital stock of inventories with labor, computer capital, furniture and fixtures capital, and buiklings capital using the Fisher formula where each 
price and quantity vector had only five components in this second stage of our input aggregation procedure, ${ }^{10}$

A further complication must be mentioned. In our data set, about 10 to 20 percent of the inventory items were either not purchased or not sold in consecutive quarters. Thus the following question arises: should we simply use the Fisher formulae (18) and (19) with zero prices and quantities inserted into the formulae for the goods that were not transacted in the periods under consideration? This problem is formally analogous to the new good problem where a new good or service appears in one period but not the prior period. A valid theoretical approach to the new good problem was originally suggested by Hicks $[1940 ; 114]:^{11}$ in periods when the new good was not available, set the quantity equal to zero and estimate a reservation price that would rationalize the zero demand or supply of the good. This same approach could be applied to the problem of infrequently transacted goods. However a practical objective to this solution to the problem is that it is difficult to estimats these reservation prices. Thus we followed the procedure that was recommended by Diewert [1980; 500]: we calculated the Fisher price index (which has the same functional form as the Fisher quantity index except that the role of prices and quantities is reversel) for each of our four inventory aggregates, except that we used price and quantity information on only those goods which were transacted in both periods. Once these restricted price indexes were constructed, the corresponding quantity indexes were defined to be the vilue ratios for goods in the aggregate under consideration divided by the correspondling restricted prices inclexes. ${ }^{12}$ The restricted price index procedure that we have just described is the one used in the econometric computer package SHAZAM; see White [1978].

We turn now to a description of our empirical results.

\section{Empirical Results}

The data cover seven consecutive quarters starting at the second quarter of 1988 . The firm's data on inventory holdings, sales and purchases are stored only for 21 consecutive months, so this was the longest period for which we could obtain data.

We distinguish five classes of net outputs: (i) sales of inventory items (SI); (ii) net additions to the stocks of inventories (AI); (iii) purchases of business services (MB); (iv)

\footnotetext{
10 Using the results in Dicwert $[1978 ; 890]$, it can be shown that Fisher quantity indexes using a two stage aggregation procedure will approximate single stage Fisher quantity indexes to the second order.

11 See also Fisher and Shell $[1972 ; 22-26]$ and Diewert $[1980 ; 501-503]$.

12 Our procedure can be related to reservation prices. For example, in (18), if the first good was not traded in period $t-1$, the Hicksian reservation price $p_{1}^{t-1}$ should somehow be estimated. Diewert $\{1980 ; 500\}$ shows that our suggested restricted price index procedure will be theoretically correct if $p_{1}^{t} / p_{1}^{t-1}=p^{t} \cdot y^{t} / p^{t-1} \cdot y^{t}$. Thus the index number bias in our restricted procedure will be zero if the reservation price $p_{1}^{t-1}$ is such that the relative clange in the price of good 1 over the two periods, $p_{1}^{t} / p_{1}^{t-1}$, is equal to the general changr in prices for the iggregate by the Paasche price index, $p^{t} \cdot y^{t} / p^{t-1} \cdot y^{t}$.
} 
purchases of shipping services (MS); and (v) purchases of inventory items for resale (MI). The quantities of the last three net outputs are indexed with a negative sign, since they are intermediate inputs. Net additions to inventory stocks was an output except for quarters 2 and 3, when inventory stocks were drawn down (and hence QAI has a negative sign for these two quarters). All prices were normalized to equal 1 in the first quarter and hence the corresponding quantities are measured in millions of constant first quarter dollars. As explained above, net outputs (i), (ii) and (v) are aggregates of 76,000 inventory items which were constructed using the restricted Fisher price index methodology explained in the previous section.

Business services that were purchased included items such as telephones services (about 30 percent of the total cost of business services), advertising and other utilities. The price index used to deflate the cost of business services was a weighted average of the all items Vancouver consuner price index and a British Columbia long distance telephone price index. ${ }^{13}$

The shipping services quantity was set equal to the number of invoices which were either delivered or picked up. The price series was derived by dividing the total cost of shipping expenses and postage by the number of invoices. We note that smaller customers did not qualify for free delivery so that shipping costs were a rather small fraction of total costs.

The quantities of the five classes of net, outputs are listed in Table 1 and the corresponding prices are listed in Table 2.

We distinguish five classes of inputs: (i) labor services (L); (ii) stocks of inventories held at the beginning of each period (KI); (iii) furniture and fixtures capital input (KF); (iv) computer hardware and software input (KC); and (v) rentals and holdings of buildings (KB). The quantity of labor services is measured in person hours ${ }^{14}$ and the corresponding wage rate includes fringe benefits. The hourly wage rate in quarter 1 was $\$ 12.87$. The inventory capital stocks are Fisher aggregates of the 76,000 inventory items and the user $\operatorname{costs} \alpha_{n}^{t}$ defined by (8) were used as price weights. The interest rate series used was the Statistics Canada series for prime business loans, which increased quite rapidly over the time period under consideration. For inputs (iii) and (iv), the user costs $\rho_{n}^{t}$ defined by (15) were used as price weights. The starting values for the quantities of these two capital stock components were taken to be the corresponding book values. The price index used for (iii) was the Vancouver price index for furniture and fixtures (from Statistics Canada) and the depreciation rate was chosen to be .05 . The price index used for (iv) was taken to

13 The Vancouver all items CPI series was $1.000,1.009,1.017,1.029,1.040,1.057$, and 1.068; the B.C. telephone price index series was $1.000, .951, .936, .789, .777, .777$ and .764 . The weight given to the telephone series was: .3. The source was Statistics Canada.

14 The number of employees was 77 
Table 1: QUANTITIES OF 5 NET OUTPUTS

\begin{tabular}{|c|c|c|c|c|c|}
\hline QUARTER & QSI & QAI & QMB & QMS & QM \\
\hline 1 & 3.0647 & 0.0071 & -0.2084 & -0.038950 & -1.9266 \\
\hline 2 & 3.1613 & -0.0384 & -0.2196 & -0.040719 & -1.6382 \\
\hline 3 & 3.1691 & -0.2724 & -0.2208 & -0.040542 & -1.5265 \\
\hline 4 & 3.2559 & 0.3832 & -0.2009 & -0.037854 & -1.9395 \\
\hline 5 & 3.3945 & 0.4636 & -0.2104 & -0.038694 & -2.0604 \\
\hline 6 & 3.4805 & 0.0165 & -0.2168 & -0.040605 & -1.7021 \\
\hline 7 & 3.5613 & 0.3920 & -0.2218 & -0.041830 & -2.0932 \\
\hline
\end{tabular}

Table 2: PRICES OF 5 NET OUTPUTS

\begin{tabular}{|c|c|c|c|c|c|}
\hline QUARTER & PSI & PAI & PMB & PMS & PMI \\
\hline 1 & 1.000 & 1.000 & 1.0000 & 1.000000 & 1.000 \\
\hline 2 & 1.013 & 1.011 & 0.9916 & 1.026667 & 1.011 \\
\hline 3 & 1.017 & 1.013 & 0.9927 & 0.980000 & 1.019 \\
\hline 4 & 1.018 & 0.999 & 0.9570 & 0.840000 & 1.026 \\
\hline 5 & 1.027 & 0.994 & 0.9611 & 0.840000 & 1.035 \\
\hline 6 & 1.046 & 0.963 & 0.9730 & 0.866666 & 1.002 \\
\hline 7 & 1.050 & 0.986 & 0.9768 & 0.913333 & 1.011 \\
\hline
\end{tabular}

be the constant 1 since the computer hardware did not change over this time period. The depreciation rate for conputers was chosen to be .30 . The starting user cost for furniture and fixtures turned out to be .1775 and the first period user cost for computers turned out to be .4025 . All price and quantity series for primary inputs were renormalized so that period 1 prices equaled unity. With respect to buildings, of the seven branches, the company owned the land and buildings in four locations and rented in the other three. However, in all four locations which were owned, the firm rented out portions of the buildings to other tenants, and these market rental rates were used as price weights for the number of square feet of space used by the firm. In period 1 , the average rental rate that the firm faced was only $\$ .133$ per square foot. In period 4, when the head office moved to Coquitlam, the average rental rate dropped to $\$ .83$ per square foot. The quantity and price information for the five classes of primary input are listed below in Tables 3 and 4 .

Table 3: QUANTITIES OF PRIMARY INPUTS 


\begin{tabular}{|c|c|c|c|c|c|}
\hline QUARTER & QL & QKI & QKF & QKC & QKB \\
\hline 1 & 0.485186 & 0.2278 & 0.051617 & 0.045321 & 0.048811 \\
\hline 2 & 0.485186 & 0.2249 & 0.062071 & 0.055343 & 0.048811 \\
\hline 3 & 0.450244 & 0.2196 & 0.071994 & 0.064601 & 0.048811 \\
\hline 4 & 0.482908 & 0.2137 & 0.078632 & 0.073295 & 0.082593 \\
\hline 5 & 0.482908 & 0.2162 & 0.076520 & 0.076434 & 0.082593 \\
\hline 6 & 0.482908 & 0.2328 & 0.074550 & 0.079373 & 0.082593 \\
\hline 7 & 0.482908 & 0.2141 & 0.072668 & 0.082069 & 0.082593 \\
\hline
\end{tabular}

Table 4: USER COSTS OR RENTAL PRICES FOR PRIMARY INPUTS

\begin{tabular}{|c|c|c|c|c|c|}
\hline QUARTER & PL & PKI & PKF & PKC & PKB \\
\hline 1 & 1.00000 & 1.000 & 1.00000 & 1.00000 & 1.00000 \\
\hline 2 & 1.00000 & 1.043 & 1.05633 & 1.02484 & 1.00000 \\
\hline 3 & 1.00000 & 1.128 & 1.06197 & 1.02732 & 1.00000 \\
\hline 4 & 1.05594 & 1.210 & 1.14535 & 1.06409 & 0.62406 \\
\hline 5 & 1.06138 & 1.273 & 1.18309 & 1.08074 & 0.62406 \\
\hline 6 & 1.06138 & 1.252 & 1.18309 & 1.08074 & 0.62406 \\
\hline 7 & 1.06138 & 1.278 & 1.18309 & 1.08074 & 0.62406 \\
\hline
\end{tabular}

We now calculate the chained Fisher net output indexes using the data in Tables 1 and 2: define the period $t$ net output growth index $Y G^{t}$ by

$$
Y G^{t} \equiv Q_{F}\left(p^{t-1}, p^{\ell}, y^{y-1}, Y^{t}\right) \quad \text { for } t=2,3, \ldots, 7
$$

The aggregate output growth series $Y G$ is tabled in Table 5 along with the period to period growth rates for cach of our five classes of net output: $S I G^{t} \equiv Q S I^{t} / Q S I^{t-1}$, $A I G^{t} \equiv Q A I^{t} / Q A I^{t-1}, M B G^{t} \equiv Q M B^{t} / Q M B^{t-1}, M S G^{t} \equiv Q M S^{t} / Q M S^{t-1}$, and $M I G^{t} \equiv Q M^{t} / Q M I^{t-1}$ for $t=2,3, \ldots, 7$. We note that it is difficult to interpret $A I G^{t}$ for $t=2$ and 4 since $Q A I^{t}$ changes sign for those two quarters. Sample averages are also included in Table 5 .

Define the chained Fisher primary input indexes using the data listed in Tables 3 and 4 ; i.e., define the period $t$ primary input growth index $X G^{t}$ by

$$
X G^{t} \equiv Q_{f}\left(w^{t-1}, w^{t}, x^{y-1}, x^{t}\right) \quad \text { for } t=2,3, \ldots, 7 .
$$

The aggregate primary input growth index $X G$ is listed in Table 6 along with the period to period growth rates for each of our five major classes of primary input: $L G^{t} \equiv$ $Q L^{t} / Q L^{t-1}, K I G^{t} \equiv Q K I^{t} / Q K I^{t-1}, K F G^{t} \equiv Q K F^{t} \equiv Q K F^{t} / Q K F^{t-1}, K C G^{t} \equiv$ $Q K C^{t} / Q K C^{t-1}$ and $K B G^{t} \equiv Q K B^{t} / Q K B^{t-1}$ for $t=2,3, \ldots, 7$. 
Table 5: GROWTH RATES FOR NET OUTPUTS AND AGGREGATE OUTPUT

\begin{tabular}{|c|c|c|c|c|c|c|}
\hline QUARTER & YG & SIG & AIG & MBG & MSG & MIG \\
\hline 2 & 1.361994 & 1.031520 & -5.408451 & 1.053743 & 1.045404 & 0.850306 \\
\hline 3 & 0.906654 & 1.002467 & 7.093750 & 1.005464 & 0.995653 & 0.931815 \\
\hline 4 & 1.305413 & 1.027389 & -1.406755 & 0.909873 & 0.933698 & 1.270554 \\
\hline 5 & 1.058764 & 1.042569 & 1.209812 & 1.047287 & 1.022191 & 1.062336 \\
\hline 6 & 1.005320 & 1.025335 & 0.035591 & 1.030418 & 1.049388 & 0.826131 \\
\hline 7 & 1.029945 & 1.023215 & 23.75758 & 1.023063 & 1.030181 & 1.229775 \\
\hline $\begin{array}{c}\text { Sample } \\
\text { Average }\end{array}$ & & & & & & \\
\hline
\end{tabular}

Table 6: GROWTH RATES FOR PRIMARY INPUTS AND AGGREGATE INPUT

\begin{tabular}{|c|c|c|c|c|c|c|}
\hline QUARTER & XG & LG & KIG & KFG & KCG & KBG \\
\hline 2 & 1.020715 & 1.000000 & 0.987269 & 1.202545 & 1.221137 & 1.000000 \\
\hline 3 & 0.977 U11 & 0.927982 & 0.976434 & 1.159851 & 1.167273 & 1.000000 \\
\hline 4 & 1.077940 & 1.072547 & 0.973133 & 1.092209 & 1.134579 & 1.692098 \\
\hline 5 & 1.004015 & 1.000000 & 1.011699 & 0.973138 & 1.042834 & 1.000000 \\
\hline 6 & 1.021582 & 1.000000 & 1.076781 & 0.974251 & 1.038441 & 1.000000 \\
\hline 7 & 0.977757 & 1.000000 & 0.919673 & 0.974761 & 1.033976 & 1.000000 \\
\hline $\begin{array}{c}\text { Sample } \\
\text { Average }\end{array}$ & 1.0132 & 1.0001 & .99083 & 1.0628 & 1.1064 & 1.1153 \\
\hline
\end{tabular}


Finally, we calculate: (i) value added in period $t, V A^{t} \equiv p^{t} \cdot y^{t}$ where $p^{t}$ and $y^{t}$ are the period $t$ price and quantity vectors obtained from Tables 2 and 1 ; (ii) cost in period $t$, $\operatorname{COST} T^{t} \equiv w^{t} \cdot x^{t}$ where $w^{t}$ and $x^{t}$ are the period $t$ price and quantity vectors obtained from Tables 4 and 3 ; (iii) profits or economic income in period $t, P R O F I T^{t} \equiv V A^{t}-C O S T^{t}$; and (iv) productivity in period $t, P R O D^{t} \equiv Y G^{t} / X G^{t}$ for $t=2,3, \ldots, T$. These series listed in Table 7.

Profits grew 19 fold over the seven quarters, value added doubled and costs grew only 18 percent over the period. The average of the quarterly productivity growth rates was 1.094 , that is, on avcrage, productivity grew at the remarkable quarterly rate of 9.4 percent. A closer examination of the data shows that most of the productivity growth

Table 7: PROFITS, VALUE ADDED, COST AND PRODUCTIVITY

\begin{tabular}{|c|c|c|c|c|}
\hline QUARTER & PROFIT & VA & COST & PROD \\
\hline 1 & 0.039113 & 0.897849 & 0.858735 & \\
\hline 2 & 0.356938 & 1.247794 & 0.890855 & 1.334353 \\
\hline 3 & 0.243024 & 1.132611 & 0.889586 & 0.927969 \\
\hline 4 & 0.495238 & 1.483337 & 0.988099 & 1.211026 \\
\hline 5 & 0.567283 & 1.579737 & 1.012454 & 1.054526 \\
\hline 6 & 0.675309 & 1.704851 & 1.029541 & 0.984081 \\
\hline 7 & 0.742408 & 1.754792 & 1.012384 & 1.053375 \\
\hline
\end{tabular}

took place going from period 1 to period 2 (a 33 percent increase) and from quarter 3 to quarter 4 (a 21 percent increase). The explanation for these large growth rates can be seen if we examine Table 7: value added increased by 39 percent going from quarter 1 to 2 and by 31 percent going from quarter 3 to 4 . This first increase in value added can be explained by the sharp decline in purchases of inventories going from quarter 1 to 2 and by the large additions to inventory stocks going from quarter 3 to quarter 4 (when the head office moved to new and more spacious quarters). The rather uneven rates of growth in purchases of inventories reflect the nature of a large distribution firm. Generally, these types of firms makc large purchases to obtain volume discounts and then specialize in having low holding costs.

6. Conclusion

Our main conclusion is that large productivity gains are possible in the distribution sector of an economy. These productivity gains are made possible by the computer revolution which allows a firm to track accurately its purchases and sales of inventory items and to use the latest computer software to minimize inventory holding costs. In our empirical example, which used the data pertaining to a large appliance distributorship in Western Canada, we found that the average total factor productivity growth rate over six quarters 
was an amazing 9.4 percent per quarter. The average quarterly growth rate for inventory sales was 11.1 percent while the average quarterly growth rate for inventory purchases was only 2.8 percent and the average growth rate for inventory stocks held was -.9 percent. Thus our distribution clcarly economized on its holdings of inventories relative to its sales of inventory items

Our empirical results appear to contradict recent research on the behaviour of inventories from a macroeconomic perspective as the following quotation indicates:

Furthermore, contrary to popular belief, inventories are not leaner now than they were decades ago. Despite the alleged revolution in inventory practices brought about by computerization, the economy-wide ratio of real inventories to real sales has been trendless for 40 years.

(Blinder and Maccini [1991; 75])

How can the above macroeconomic "facts" be reconciled without microeconomic "facts"? A possille explanation is that the number of commodities that are sold on world market has been dramatically expanding in recent years. For example, from 1984 to 1990 , the number of standard chemical products that are carried by a leading chemical supply company ${ }^{15}$ for immediate delivery has risen from 16,000 products to 27,000 products. Each new product requires a separate inventory. Hence if computer induced inventory economics werc not occurring at the micro firm level, we would expect macro inventory stocks to be growing faster than sales if new products were being introduced into the economy on a widespread basis. Thus the above macro "facts" can be reconciled with the microeconomic results that we obtained, if there was a widespread proliferation of new products into the world economy during the past 40 years (which we believe has taken place).

15 The company is Aldrick Chemical Company [1984] [1990]. In addition to its standard chemical products listed in its main catalogues, this company offered an additional 23,000 rare chemicals in 1984 and an additional 33,000 rare chemicals in 1990. In both 1984 and 1990, the company stated that approximately 4,000 of its standard chemical products were new. 


\section{REFERENCES}

Aldrick Chemical Company [1984] [1990], Catalog/Handbook of Fine Chemicals, Milwaukee: Aldrich Chenical Company.

Blinder, A.S. and L.J. Maccini [1991], "Taking Stock: A Critical Assessment of Recent Research on Inventories," The Journal of Economic Perspectives 5, 73-96.

Christensen, L.R. and D.W. Jorgenson [1969], "The Measurement of U.S. Real Capital Input, 1929-1967". Review of Income and Wealth 15, 293-320.

Diewert, W.E. [1978], "Superlative Index Numbers and Consistency in Aggregation", Econometrica 46. 8\$3-900.

Diewert, W.E. [1980], "Angregation Problems in the Measurement of Capital", pp. 433-528 in The Measurement, of Capital, Dan Usher (ed.), Chicago: The University of Chicago Press.

Diewert, W.E. [1992], "I"isher Ideal Output, Input and Productivity Indexes Revisited", Journal of Productinity Analysis 3, 211-248.

Fisher, I. [1922]. The Muling of Index Numbers, Boston: Houghton-Mifflin.

Fisher, F.M. and K. Shll [1972], The Economic Theory of Price Indexes, New York: Academic Press.

Hicks, J.R. [1940]. "The Valuation of the Social Income", Economica 7, 108-124.

Jorgenson, D.W. [1963]. "Capital Theory and Investment Behaviour", American Economic Review 53, 247-259.

Jorgenson, D.W. and Z. Griliches [1967], "The Explanation of Productivity Change", The Review of Economic: Studies 34, 249-283.

Statistics Canada [1985]. Gross Domestic Product at Factor Cost by Industry, Cat. No. 61-213, Ottawa: Stal istics Canada.

United Nations [1968]: A System of National Accounts, New York: United Nations.

United Nations [1993]. System of National Accounts 1993, New York: United Nations.

White, K.J. [1978], "A G'(neral Computer Program for Econometric Methods - SHAZAM", Econometrica 46, 23!)-240. 